\title{
Editorial
}

\section{Informed Consent: Are We There?}

\section{Joseph A. Spinnato II, MD Perinatology Editor}

The current standards for patient informed consent have evolved from concepts generated in the 1960's and 1970's by the then "new" discipline of medical ethics; these concepts, for all intents and purposes, previously were absent from clinical medicine and research. We have moved from a time of unchallenged medical authority, research with no anticipation of benefit to the studied subjects, and the near complete acceptance by patients of the recommendations from their physicians to a time where governing organizations such as the American Medical Association, the American College of Obstetricians and Gynecologists (ACOG), and the American Academy of Pediatrics have adopted recommendations for informed consent that embrace respect for the autonomy of the patient as the singularly most important consideration.

As defined by Beauchamp and Childress, ${ }^{1}$ informed consent is the autonomous authorization by individuals of a medical intervention or of participation in research. The authors describe seven elements of consent that are necessary to preserve the patient's autonomy: (1) competence, (2) voluntariness, (3) disclosure (of adequate information), (4) recommendation (of a plan), (5) understanding, (6) decision, and (7) authorization. Largely, these elements have been adopted in the policy statements of the aforementioned organizations. In many respects, the development of informed consent has been spurred by the malpractice environment within which we practice, molded by lawyers and risk managers; sadly and too often, the consent process appears to be intended primarily to be protective of physicians and hospitals rather than to improve care.

Arguably, nowhere in medicine are the issues and decisions involving informed consent more complex than in the areas of women's health and perinatal medicine. Whether counseling is by the gynecologist regarding contraception, sterilization, or abortion; by the obstetrician/perinatologist regarding prenatal diagnosis, fetal anomalies, selective reduction of multiple gestation, or decisions at the limits of fetal viability; or by the pediatrician/ neonatologist regarding issues of extreme prematurity or severe anomalies of the newborn, the decisions by the patients involve beginning-of-life issues that add a layer of complexity to the elements listed above. A woman's decision begins with the informa-

School of Medicine, University of Louisville, Louisville, KY.

Address correspondence and reprint requests to Joseph A. Spinnato II, MD, School of Medicine, University of Louisville, Louisville, KY 40292. tion and recommendations of her care provider. This decision is modified by religious, moral, ethical, cultural, pragmatic, and genderspecific considerations that are often poorly understood or unexplored by the care provider. The decisions involve issues of patient autonomy, beneficence-based obligations to a fetus or newborn, legal constraints, societal norms, and family considerations that are complex and bewildering to the most sophisticated patients.

We often elicit these decisions from young patients who, frequently, have not made adult determinations of their moral and ethical beliefs. Many of the patients for whom we care are facing such complex decisions for the first time in their lives; they are ill-equipped to integrate this myriad of factors into a decision that reflects more than an emotionally driven guess at an answer. The patient who regrets terminating (or not terminating) a normal or abnormal pregnancy may not have changed her mind, but simply may have selected a course of action initially that did not reflect cognitive processing.

In light of these considerations, the informed consent burden on the caregiver is immense. Frequently, when faced with time constraints, the complexity of issues, the uncertainty of the patients' religious and ethical beliefs, and the presumed limited ability of the patients to formulate decisions that will work for them over time, the consent process can become short-circuited, directive, and paternalistic. By selectively withholding, minimizing, or magnifying information provided to the patient, the practitioner may facilitate a decision that either suits the presumed needs and best interests of the patient or, of greater concern, suits the practitioner's opinion of the best needs of the family, society, third-party payers, or other vested party with limited regard to the best interests of the patient or her fetus. Such counseling can be deceptive and represent a negative paternalism that is rarely, if ever, justifiable.

On the level of public policy, I previously have expressed my concern $^{2,3}$ that the literature, medical texts, and patient information inserts that minimize or do not address the postfertilization mechanisms of action of intrauterine contraceptive devices and postcoital emergency contraception may serve to thwart informed consent by skirting potential moral objections to these technologies, thereby facilitating decisions with less than appropriate regard for potential religious and ethical concerns of the patients. Similarly, ACOG's definitions of conception (a synonym for implantation) and pregnancyonset (at implantation), which are in sharp contrast to the common lay, religious, and embryologists' definitions of conception and pregnancy-onset (fertilization), appear to threaten informed consent ${ }^{3}$ by obfuscating moral issues in the interval from fertilization to implantation. 
Have we advanced our understanding and practice of informed consent? Without doubt, we have. Do we consistently employ a consent process that is based upon the principle of patient autonomy? Perhaps we do not. The need for considerable physician input into the decision process challenges the physician to gather enough information from the patient and to provide enough information to the patient so that she can arrive at a decision largely on her own merits. In these instances involving the beginnings of life, rather than facilitating a decision that we assume fits her beliefs, it is reasonable to expect physicians to provide accurate information (e.g., the mechanisms of action of contraceptives and intact survival statistics at the limits of viability) and then to guide the patient to a decision that, within legal constraints, fits her values and beliefs.

The current model of informed consent was developed largely by men and is primarily founded on and reflective of the importance that men attach to the principles of autonomy and justice. A strong argument has been made that the concerns of women are not as strongly linked to these principles as are they for men. The care ethic $c^{4}$ championed by Carol Gilligan notes that women have an understanding of life that focuses on interdependence and caretaking, while accepting limits to autonomy and control. Personal justice, if you will, takes a back seat to nurturing and interconnection. To paraphrase Baier, ${ }^{5}$ informed consent, like the best moral theory, has to harmonize justice and care. Add to this the issue of goodness described by the ethnics of virtue $^{1}$ and we begin to understand that current informed consent may inadequately serve our patients' needs.

Our current informed consent method is a work in progress. For improved patient care and improved physician-patient relationships, informed consent must mature beyond the mere legal mechanism that it so often represents and become focused on helping our patients. We must better address the needs of women, moral issues at the beginnings of life, the negative influence of paternalism, and the importance of ethical theories of personal and societal rights and responsibilities so as to strike a balance between social justice and our patients' needs.

\section{References}

1. Beauchamp TL, Childress JF. Principles of Biomedical Ethics. 4th ed. New York: Oxford University Press; 1994.

2. Spinnato JA. Mechanism of action of intrauterine contraceptive devices and its relation to informed consent. Am J Obstet Gynecol 1997;176:503-6.

3. Spinnato JA. Informed consent and the redefining of conception: a decision illconceived? J Matern Fetal Med 1998;7;264-8.

4. Gilligan C. In a Different Voice: Psychological Theory and Women's Development. Cambridge, MA: Harvard University Press; 1982.

5. Baier A. The Need for More than Justice: science, morality, and feminist theory. Can J Phil 1987;13:41-56. 